\title{
Investigation of the Focal and Zoom Properties for Three-Element Cylindrical Electrostatic Lens
}

\author{
Nedhal S. A. Hujazie \\ Department of Basic Sciences \\ College of Agriculture and Forestry \\ Mosul University \\ E-mail:nedhal_sadie2000@yahoo.com
}

(Received 28 / 12 /2009 ; Accepted 7/ 6/2010)

\begin{abstract}
In the present work, the focal properties of electrostatic lens consist of three cylindrical electrodes were intensively investigated . Each electrode spaced of (0.1) diameter apart. Special case such as a zoom lens is considered and the results are obtained as a function of the final-to-initial voltage ratios. It is found that the three-element lens could be operated with the whole focus properties in a useful mode. The calculations are carried out by using the LENSYS software package.
\end{abstract}

Keywords: Three-element electrostatic lens, Focal properties, Zoom lens, LENSYS.

\section{لمقفصاء الخواص البصربة لمسة كهروستلتيكية (Zoom Lens) ذلت غلاث أنهلب المطوانية}

\section{|لمالخص}

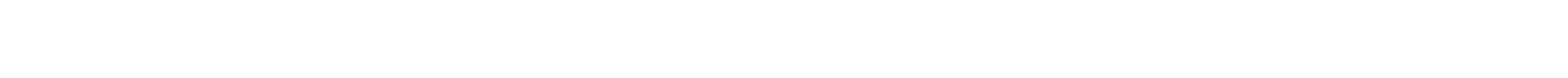

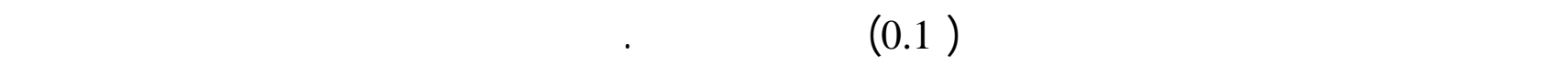

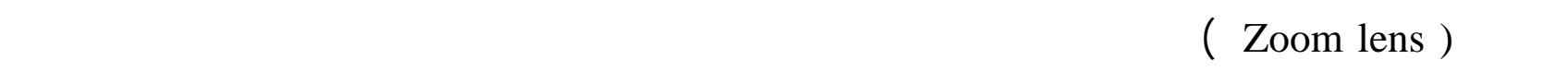

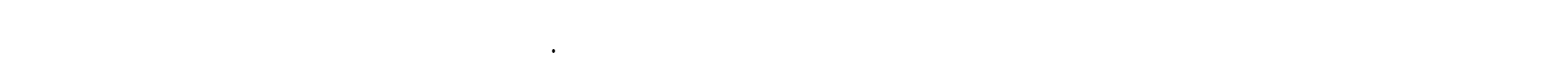
. LENSYS برمجيل 